\title{
Improving the Reproductive Health Status of Rural Women of Umunze in Orumba South of Anambra State, Nigeria
}

\author{
Edith Uju Enemuoh \\ Department of Home Economics, \\ Federal College of Education (Technical), \\ Umunze, Anambra State, Nigeria.
}

\section{Doi:10.5901/mjss.2013.v4n7p67}

\begin{abstract}
The study was focused on improving the Reproductive Health Care Status of women in rural areas with a case study in Umunze in Orumba South Local Government Area of Anambra State. Specifically, the study identified and assessed some reproductive health care practices as adopted by the women in rural areas, impediments to attaining adequate reproductive health care and strategies for improving reproductive health status of the rural women in the area of the study. Descriptive survey that utilized questionnaire was used for data collection. The target population consisted of all women of reproductive and child bearing age. Percentages were used to analyze the data. Ten major findings were identified and these were enumerated within the study followed by recommendations.
\end{abstract}

Keywords: Health, Reproductive Health, Motherhood, Family Planning, Contraceptives.

\section{Introduction}

Health according to the World Health Organization (WHO, 1991) is a state of complete physical, mental and social well being and not merely the absence of disease or infirmity. Reproductive health therefore involves all the reproductive systems, processes and it functions at all stages of life. In line with WHO's definition of health, the International Conference of Population and Development (ICPD, 1994) defined reproductive health as a state of complete physical, mental and social well being and not merely the absence of diseases or infirmity in all matters related to reproductive systems, its functions ands processes. Reproductive health thus, demands that people are able to have a responsible, satisfying and safe sex life. The individual's also have the capability to reproduce and the freedom to decide if, when and how often to do so. Reproductive health also includes the right of men and women to be informed and to have access to safe effective, affordable and acceptable methods of family planning of their choice (ICPII, 1994).

The components of Reproductive Health as stated by Population Reports (1996) (ICPI, 1994) and WHO (1994) include among others, responsible reproductive sexual behavior, family planning programmes which focus on providing information and services on contraception widely, effective maternal care, safe motherhood which ensure that pregnant women would receive adequate pre-natal, safe delivery and post natal care.

In order to ensure adequate and appropriate reproductive health for women particularly in the rural areas, women should be exposed to appropriate health care services that will enable them to go safely through pregnancy and child birth while providing them with best choice of health for infants. Women in developing countries like Nigeria are often subjected to health risks due to inadequate responsiveness and lack of health services to meet their health needs particularly with regards to sex and reproduction. (United Nations, 1996) in a typical Nigerian culture with a focus on the area of study which is Umunze, observations and oral interviews conducted and among sampled group indicate that male dominance of decision making 
on reproductive health matters and related issues and sometimes their opposition of fertility regulation represents an important barrier to wishes use of reproductive health care facilities by women. Again, the relatively low status of the women within the family as obtained in most Nigerian cultures particularly in Anambra State; often impair the rights of women to adequate reproductive health care, since this fact makes their wishes subordinate to that of their husbands.

The rural women are the focus of this study since majority of them who live in the rural areas, are mostly illiterates and thus have limited access to reproductive health care information system. The custom, tradition and lower status of women in the family also place them at a disadvantaged position to benefit much from reproductive health care initiatives. Pregnancy and child have been identified as leading causes of mortality and mobility of women in their reproductive and child bearing age (Arkutu, 1995).

Statistics from Population Reference Bareau (1997), UN (1994) and Arkutu (1995) indicate that these reproductive health care problems and their complications are pronounced in developing countries like Nigeria. Again, the existing health problems persist because there is a general lack of basic infrastructures for a sound health care system. In a place like Umunze, the area of study, investigations reveal that only one health center is available which definitely does not serve the rural women who dwell there, who as a matter of fact are predominantly farmers, which indicates that they seldom have time spared for other activities outside their farming more so when the health faculty fails to provide adequate medical and reproductive health care services and a functional Health Management Information System (HMIS). This system is necessary to help provide relevant health data and health assessment to the reach of the people easily and at affordable cost.

The question here is how can the Reproductive Health Care Status of Rural women be improved particularly in the area of the study where the researcher chose for reasons of their predominant occupation which seldom gives them the opportunity for other aspects of life?

What impediments are identified as affecting the reproductive health life of the rural women in the area of study, what strategies can be adopted to help improve the reproductive health life of these women? These and other questions are what this study seeks to obtain answers to at the end of the research.

It is believed that the more alternatives and choices the rural women in Anambra State have, as will be highlighted in the study, the more likely the rural women will be willing and able to utilize the services and facilities available.

\section{Statement of the Problem}

Pregnancy and child birth have been identified as leading causes to mortality and morbidity of women in their reproductive and child bearing age (Arkutu, 1995). Population Reference Bureau PRB (1997) noted in a summary of findings that 585,000 women die every year from complications of pregnancy, childbirth and related causes. Ninety-nine percent of these women come from developing countries like Nigeria of which Umunze the area of study is one of them.

Women in these areas face greater risks during pregnancy, childbirth and post-partum periods, as a result of limited access to reproductive health facilities which automatically help to improve on their reproductive health generally. Of serious concern is the status of the rural dwellers who are mostly illiterates and predominantly have an impaired access to adequate medical and reproductive health care services, in addition to a moribund health system due to conspicuous absence or lack of functional health management information system (HMIS). For the area of study-Umunze, one wonders what help just one health facility/centre located in the town could offer to most of its women who are predominantly housewives and fully involved in reproductive health care practices. The alternatives these women have are the privately owned hospitals and few mission hospitals which often times scare these women away with huge medical bills. Previous researches and observations show that most reproductive health care facilities even when they are available are seldom used by these women particularly the rural women due to ignorance and oftentimes cultural obligations. The relatively low status of women in most Nigerian families, place the 
women at disadvantaged positions in terms of acquiring adequate reproductive health care. It is believed that when these problems are well addressed as it affects the rural women in Orumba South Local Government area; it will go a long way to improving and ensuring the over all health care of these women.

The focus of this study is primarily on improvement of the Reproductive Health Care Status of rural women in Umunze in Orumba South Local Government Area.

Specifically, the study is aimed at:

1. Identifying some Reproductive Health Care practices by the rural women in Umunze, Orumba South Local Government Area.

2. Identifying some major impediments to the acquisition of adequate reproductive health care by these women in the area of study.

3. Identifying and recommending some strategies that will help improve the Reproductive Health Care Status of the rural women in the area of study.

\section{Significance of the Study}

In Anambra State in general and Orumba South Local Government Area with particular focus on Umunze, the tradition, custom and lower status of women in the family places the man higher in taking reproductive health decisions. This is complicated by the fact that most of these rural women are illiterates and thus, have limited to reproductive health and information services etc.

It is therefore believed that the findings and inputs of this study will expose the women's ignorance about much of her reproductive health needs which will form a good basis for fortifying the health clinics and centers in various localities particularly in the area of study Umunze.

The findings of the study will also strengthen the ability of women to make reproductive health decisions in the family by increasing their self esteem and confidence in choosing reproductive health care devices as it soothes their personality, without the influence of culture or tradition.

Suggestions and inputs of this work will go a long way to throw more light on areas of reproductive health care of the women that needs improvement.

Government communities and different localities can benefit immensely from the findings of this research work by adopting the strategies enumerated for an improved adequate health management information system where women can always resort to for enlightenment and health information.

Finally, the findings of this study will form a good resource material for individuals who want to carry out further researches in related areas.

\section{Methodology}

The design adopted for the study was survey research. This was particularly preferred because it will have a direct contact with the respondents and help to elicit more responses. The area of the study is Anambra State but for the purpose of the study, Umunze in Orumba south Local Government Area was used for the study. The population comprises of all women of child bearing or reproductive age in the areas of the study, (Orumba South Local Government Area in Anambra State).A total of 160 respondents were drawn randomly from the 4 zones in the town used for the study. For the purpose of the study, the area of study was divided into 4 zones considering all the villages in the area. In each zone, 40 respondents were randomly selected making a total of 160 respondents. The household was used as a unit of observation.

Questionnaire was used to collect the data. This was developed based on the review of related literature and the purpose of the study. One hundred and sixty copies of questionnaire were distributed to the respondents (women) in the selected areas. The questionnaires were translated into vernacular language for the very illiterates women who cannot read or interpret the items on the questionnaire. The 
completed questionnaires were collected on the spot to ensure $100 \%$ return. The collected 160 questionnaires were subjected to data analysis.

The data collected were analyzed using simple percentages. Any response above $50 \%$ was taken as accepted and vice versa.

\section{Results}

Table I: Responses on the Reproductive Health Care practices as adopted by women in Umunze, Orumba South Local Government Area.

\section{S/N ITEMS}

1

Familiarity with the proper and frequent usage of family planning devices e.g. pills , IUDs, Diaphragms, condoms, foaming tablets etc.

2 Regular usage of family counseling services available within the area.

3 Attending regular pre-natal, delivery and post-natal services.

4

5

6

6

Eating adequately and properly balanced food before and during pregnancy to enhance reproductive health.

Playing the same role with husband in reproductive health decisions as regards child bearing and family planning strategies.

Being available for regular medical check-ups and enlighten seminars and workshops available within the area.

Strict adherent to cultural rules, norms and taboos at the detriment of adequate reproductive health care.
YES \% NO \%

$\begin{array}{cc}25 & 75 \\ 37.5 & 62.5 \\ 65 & 35 \\ 47.5 & 52.5 \\ 38.7 & 61.3 \\ 31.2 & 68.8 \\ 43.8 & 65.2\end{array}$

The items and the responses on the above table 1 show that the respondents (rural women) generally have a poor attitude to adopting healthy reproductive health care practices. This is evident from the negative responses on items $1,2,4,5,6$ and 7 with percentage responses of $75,62.5,52.5,61.2,68.8$ and 56.2 respectively. Since these items score above $50 \%$ which is the cut off point, it is therefore accepted that the negative responses to the healthy reproductive health care habits is indicative of poor reproductive health care practices by the women.

Table II: Responses on the impediments to obtaining adequate Reproductive Health Care among rural women in Umunze Orumba South Local Government Area.

$\begin{array}{clcc}\text { S/N } & \text { ITEMS } & \text { YES } \% & \text { NO \% } \\ 1 & \text { Low literacy level of the women } & 72.5 & 27.5 \\ 2 & \text { Influence of husband } & 65.6 & 34.4 \\ 3 & \text { Societal/traditional/cultural norms and influence } & 53.1 & 46.9 \\ 4 & \text { Influence of religion } & 55.6 & 44.4 \\ 5 & \text { Non-availability of facilities } & 75 & 25 \\ 6 & \text { Non functionality of available reproductively Health care facilities } & 81.3 & 19.7 \\ 7 & \text { Expensive nature of some reproductive health care facilities } & 11.2 & 88.8 \\ 8 & \text { Users choices of reproductive health care are not considered } & 53.1 & 46.9 \\ 9 & \text { Method of dispensing facilities do not meet the users needs } & 55.6 & 44.4 \\ 10 & \text { In accessibility to most rural areas. } & 63.8 & 36.2 \\ 11 & \text { Communication problems/lack of awareness } & 78.1 & 21.9\end{array}$

The analysis in table II above clearly show that most of the items enumerated under the table, as impediments to the Reproductive health care of the rural women were accepted with percentage scores 
above $50 \%$ the cut off point. Item 7 was however observed to be below the cut off point with a percentage response $11.2 \%$. This means that the item was not seen as an impediment or obstacle to the women's reproductive care attainment.

Table III: Responses on strategies for improving the Reproductive Health Care status of the rural women in Umunze, Orumba south Local Government Area.

\section{S/N ITEMS}

1 Reproductive health care faculties and information to be made easily available.

2 Women should be given the opportunity and freedom to choose any family planning device of their choice and reproductive health decisions.

3 Accessibility to these facilities must be a priority so as to ensure adequate reproductive health care.

$4 \quad$ Societal, religious, cultural and family norms and values should be adjusted to suit the women's reproductive health needs.

Educating and enlightenment of the women on reproductive health matters regularly should be a must.

Fortified health centers/clinics with learned personnel should be provided for the women in accessible areas, to enhance utilization ability. Establishing means of enhancing the nutritional status of most women which will automatically improve their health status. rural women will ensure improved reproductive health care.

$\begin{array}{cc}\text { YES \% } & \text { NO \% } \\ 55.8 & 46.2 \\ 55.6 & 44.4 \\ 71.9 & 28.1 \\ 61.3 & 38.7 \\ 55.6 & 44.4 \\ 78.1 & 21.9 \\ 61.9 & 38.1 \\ 86.3 & 13.7\end{array}$

The data on table III above reveals that all the factor (items) enumerated were strongly endorsed by the respondents as strategies for improving the reproductive health care status of the women. On the table item recorded a highest \% response of 86.3 while item 5 had the least percentage response of 55.6

\section{Major Findings}

The following findings were made;

1. The rural women in the area of study, were not familiar with and do not regularly use the family planning devices available proper

2. Nutrition was not considered as a vital factor in enhancing reproductive health hence their poor attitude to feeding practices

3. The rural women were very highly marginalized in items of taking decisions on reproductive health matter

4. Health practices like regular medical check ups, and attending enlightenment seminars and workshops on reproductive health issues was not regularly practiced by women ,

5. Reproductive health care facilities are not easily available and accessible to the rural women in Umunze.

6. Non- functionality of most facilities available for the women in the area.

7. Inaccessibility to most rural area to disseminate information on reproductive health care matters

8. Influence of husbands, religion, culture, tradition, and some taboos were major impediments to achieving proper reproductive health by the women.

9. Providing incentives like free medical and reproductive health cares can go a long way to boosting and sensitizing the women into achieving proper reproductive health status.

10. Making the facilities available and accessible to the women is also a major strategy for improving the women s reproductive health. 


\section{Discussions}

The finding of the study show that cultural and traditional factors, food taboos like what a woman should eat and what should not eat during pregnancy, socio-economic factors, male dominance in decision making, are all areas that clearly discriminate against the rural women and place them on disadvantage position as far as achieving proper reproductive health status is concerned. McCauley et al (1994) supported this observation when they noted custom, tradition and beliefs of a people as obstacles to obtaining adequate health information by most women particularly in the rural areas. Poor nutritional habits and poor medical habits were noted as some of the practices by the Arkutu (1995) was often more prevalent among women in developing countries like Nigeria particularly in the rural areas. Since women have special and additional need for nourishment hence they bear and nurture children, Arkutu (1995) again noted that they are more likely to suffer under-nourishment which will automatically affect their unborn babies.

Again male dominance in decision making was identified as a strong factor in reproductive health matters. This according to WHO (1995) was attributed to the relatively low status of the women in the society which make their decisions subordinate to that of their husbands. Other factors which formed major impediments to the women's reproductive health include low literacy level of most of the women which literally places them at disadvantaged positions. To this Arkutu (1995) observed that the more educated a women is the more likely she is to make right decisions concerning her health and that of her children.

The findings also noted that women need to be empowered to enable them to have health freedom. Empowerment according to WHO (1992) is critical to securing safe motherhood because it enables women to articulate their needs and concerns. Empowering women means enabling them to overcome these barriers and to make fully informed choices particularly in the areas affecting the most intimate aspects of their lives. WHO (1998) rightly supported this by saying that empowering the women in the area of health requires more than health related interventions, it requires a social, economic and cultural conditions in which freedom and responsibility are given concrete manning. Women particularly the rural women must have the means both physical and psychological to overcome barriers to safe motherhood.

\section{Conclusion}

Based on the findings of this study, the conclusions can be drawn:

1. Most reproductive health care facilities are not readily available for the women in Umunze, Orumba South Local Government Area.

2. Majority of the rural women do not practice healthy reproductive care practices and these affect their health status.

3. Most rural women in the area lack proper information on the utilization of these reproductive health care facilities.

4. Husbands have greater influence on reproductive health matters than the women.

\section{Recommendations}

The following recommendations are therefore made based on the findings:

1. Women should have access to accurate information about their reproductive health as well as to properly equipped women centered care.

2. Reproductive health care information must be seriously taken to the grass roots and efforts made to protect the rural women from most traditional cultural norms and values that affect their reproductive life.

3. Women should be allowed greater freedom to determine their own health and life choice within families and communities. 
4. Government/communities should provide well fortified health and delivery centers for quality maternal care and child delivery. These should be located in various localities and made accessible to the women.

\section{References}

Arkutu, A.A. (1995). Healthy Women, Healthy Mothers. An Information Guide (2nd edition): family Care International Inc. FRCOG, USA.

International Conference on Population and Development (1994). United Nations Publications: No. E. 95. XIII, 18 Cairo 5-13 September.

McCauley, A.P. Robbey, B; Blanc, A.K. \& Geiller, J.S. (1994). Opportunities for Women Through Reproductive Choice. Baltimore, Maryland: John Hopkins School of Public Health, Population Information Programme, Population Report, Series M. No. 12. January 40 pp.

Population Reports (1985). Youths in the 1980's. Social and Health Concerns. Series M. No. 9. Baltimore, John Hopkins University, Population Information Programme November, December 38 pp.

Population Reports (1989). Promoting Family Planning with Television, Video and Film. Series J. No. 38. Baltimore, John Hopkins University, Population Information Programme November, December 31 pp.

Population Reference Bureau (1997). Population and Reproductive Health in Sub Saharan Africa. Population Bulletin: 52. (4) December $44 \mathrm{pp}$.

Reproductive Health Research (1993). Challenges in reproductive Health Research. Biannual Report 1992-1993, WHO, Geneva.

Reproductive Health Research (1997). The New Directions. Biannual Report 1996-1997, WHO, Geneva.

United Nations (1996). Women's Education and Fertility Behaviour: Recent evidence from the Demographic and health survey: Sales No. E 95. XIII. 23.

World Health Organization (1986). Prevention of Meternal Mortality Report of WHO Inter-regional Meeting Geneva 11-15 November 1985 Geneva. WHO, 23 pp (Mimeo).

World Health Organization (1991). Maternal Mortality ratios and rates: a tabulation of available Information (2 ${ }^{\text {nd }}$ edition) Geneva, WHO, 100 pp.

World Health Organization 91992). Approaches to Adolescent Health and Development: A compendium of Projects and Programmes, Geneva, WHO, $287 \mathrm{pp} /$

World Health Organization (1994). Women and AIDS: Agenda for Action. Geneva: WHO, in collaboration with the United Nations Development Programmes and the United Nations Secretariat, Department for Policy Coordination and Sustainable Development, division for the advancement of women.

World Health Organization (1995). Adolescent Health and Development: The Key to the Future. Paper prepare for the Global Commission on Women's Health WHO/ADH/94.3/Rev.1.Geneva.

World Population Monitoring (1996). Selected aspects of Reproductive Rights and Reproductive Health. New York. Population division. ST/ESA/SFR.A/156. 
